\title{
Effects of an increase in trap mesh size on an overexploited coral reef fishery at Discovery Bay, Jamaica
}

\author{
Zsolt Sary $^{1,2}$, Hazel A. Oxenford ${ }^{1, *}$, Jeremy D. Woodley ${ }^{2}$ \\ 'Marine Resource and Environmental Management Program (MAREMP), University of the West Indies, Cave Hill, \\ Bridgetown, Barbados \\ ${ }^{2}$ Centre for Marine Sciences, University of the West Indies, Mona, Kingston 7, Jamaica
}

\begin{abstract}
One of the most popular management tools for Caribbean reef fisheries is a minimum mesh size for traps. It is believed that increasing the mesh size of traps in overexploited fisheries will result in higher catch rates in the long term, but lower catch rates in the short term. This study represents the first attempt to document the short-term and long-term effects of partly replacing small mesh with a larger mesh size in an artisanal coral reef fishery. A community level mesh exchange program was initiated in the Discovery Bay trap fishery in March 1991, whereby active fishers were given large mesh $(1.5$ inch: $3.8 \mathrm{~cm})$ wire to construct traps in exchange for handing in their small mesh $(1 \mathrm{inch}$ : $2.5 \mathrm{~cm}$ and $1.25 \mathrm{inch:} 3.2 \mathrm{~cm}$ ) traps. Although the total number of active traps and the total number of hauls per month did not significantly change in the fishery, the proportion of small mesh traps decreased substantially as a result of the mesh exchange program, leading to a concurrent reduction of fishing mortality in smaller sized fish. Changes in the fish populations were examined by comparing catch-per-unit-effort (CPUE as number of fish per trap per haul, and $\mathrm{kg}$ per trap per haul); mean size of individual fish; catch composition; and length frequency distributions for the 2 most common species, for both 1.25 inch and 1.5 inch traps in 3 separate 6 mo periods (July to December) in 1990 (10 mo before the implementation of the mesh exchange program), 1991 (immediately after the implementation of the mesh exchange program) and 1994 ( 3 yr after the implementation of the mesh exchange program). The results indicate that reef fish populations at Discovery Bay, and hence yields to the fishery, have increased in the $3 \mathrm{yr}$ since the mesh exchange program was implemented. The number of fish caught per trap haul has increased; the total weight of the catch per trap haul, at least of the smaller mesh sizes, has increased; the catch composition has shifted towards larger and more valuable species; the mean size of fish taken by the fishery is larger; and the population of 1 narrow-bodied species investigated has shifted towards larger size classes since the increase in mean mesh size in the fishery. However, despite an increase in the gross catch per week by the trap fishery, catch rates still differ markedly between small and large mesh traps, with small mesh traps catching less per haul but more per week than large mesh traps. As a consequence, fishers still using small mesh traps are benefitting the most from recovery of the reef fish populations, which demonstrates the need for further efforts to eliminate the smaller mesh traps from the fishery.
\end{abstract}

KEY WORDS: Coral reef fishery $\cdot$ Trap mesh size $\cdot$ Fishery management

\section{INTRODUCTION}

The focus of this study is the artisanal trap fishery of Discovery Bay, on the north coast of Jamaica $\left(18^{\circ} 28^{\prime} 00^{\prime \prime} \mathrm{N}, 77^{\circ} 24^{\prime} 30^{\prime \prime} \mathrm{W}\right)$, a locally important fishery which provides essential protein and employment

-Addressee for correspondence.

E-mail:maremp@sunbeach.net to the economically depressed coastal community (Berkes \& Shaw 1986, Allison 1992, Aiken 1993, Sandeman \& Woodley 1994). However, the coral reefs on this coast of Jamaica are thought to be among the most overfished reefs in the English-speaking Caribbean (Government of Jamaica 1994, Hughes 1994, Roberts 1995). This trap fishery is nevertheless typical of many others throughout the Caribbean, which are producing yields considerably lower than estimated potential 
long-term sustainable yields as a result of depressed stock abundances caused by a combination of overexploitation and habitat degradation (e.g. Munro 1983, Rogers 1985, Russ 1991, Bohnsack 1993, FAO 1993, Hunte \& Mahon 1994, Koslow et al. 1994). The catches are characterized by a high proportion of low valued species, a small mean size for all species, and a scarcity or even complete disappearance of the larger species (e.g. all large Serranidae; Sary 1995).

Management of trap fisheries in the Caribbean, and particularly management of the Jamaican north coast trap fishery, is urgently needed, but presents many difficult problems (Munro \& Smith 1984, Mahon 1990, Koslow et al. 1994). For example, the very large fishery on this coast, with approximately 2450 licensed fishers using about 900 registered boats, is concentrated on a very narrow ( $<1 \mathrm{~km}$ wide) island shelf. In addition, a large proportion of fishers are not licensed and boats are not registered. The fishery uses a relatively nonselective gear, and the multi-species catch is landed at many dispersed landing sites (79 are officially recognized by the Data Collection Unit of the Jamaican Fisheries Division) along the $250 \mathrm{~km}$ coastline. The situation is exacerbated by the fact that the fishery has a tradition of unlimited entry, that the fishing grounds are easily accessible, that the resource is already heavily overexploited, and that alternative employment opportunities are lacking (Allison 1992, Chakalall 1992, Aiken 1993). As a consequence, the Jamaican north coast trap fishery, like many other trap fisheries in the region, is almost completely unregulated. However, most countries in the region are attempting at least partial management of their trap fisheries (e.g. Mahon 1987, Burnett-Herkes \& Barnes 1991, Chakalall 1992, Kimmel \& Appledorn 1992, NMFS 1996).

Management tools considered suitable for reducing fishing mortality in reef fisheries include gear restrictions, fish sanctuaries, and limited entry. There are several reviews of management options for reef fisheries (e.g. Munro \& Williams 1985, Mahon 1990, Medley et al. 1993, Sale et al. 1994, Munro 1996). One of the most popular proposed management tools for Caribbean reef fisheries is a minimum mesh size for traps (CFMC 1985, Mahon 1990, Chakalall 1992, Hunte \& Mahon 1994). It is argued that a minimum mesh size regulation could alleviate overfishing by reducing mortality of juvenile fish (Hunte \& Mahon 1994). Thus, increasing the mesh size of traps in overexploited fisheries is expected to result in higher catch rates in the long term after fish population biomass has increased, but lower catch rates in the short term as catch rates of juveniles are reduced (CFMC 1985). However, there is currently little information available to managers on the time frame that would be required for catches to improve, except for the growth rates of some species (Munro 1983, Picou-Gill et al. 1991), nor is there general agreement on what minimum mesh size is most appropriate to enhance reef fisheries (Hunte \& Mahon 1994). All previous field studies of fishtrap mesh size selectivity have compared catch rates of different mesh size traps fished in the same area at the same time. The results of these studies may not, therefore, be appropriate to estimate long-term catch rates of some mesh sizes, because the sampled fish populations are not in equilibrium with all the mesh sizes used in the experiment (Hunte \& Mahon 1994). This study represents the first attempt to document the short-term and long-term effects on the resource of introducing a larger mesh size, partly replacing small mesh sizes, in an artisanal trap fishery. Specifically, we examine changes in catch per trap haul and catch composition (by family group) immediately after and $3 \mathrm{yr}$ after implementation of the mesh exchange program, in an attempt to understand and quantify any changes in fish abundance and community structure, and to consider the implications of these changes for fishers. We also examine changes in the mean size and length-frequency distribution of 2 common species immediately after, 1 yr after and 3 yr after implementation of the mesh exchange program, in an attempt to monitor and interpret shifts in population size structure of these species following the mesh exchange, and use these results to make inferences about other members of the reef fish community.

\section{METHODS}

Introduction of a larger mesh size. A community level mesh exchange program was initiated in the Discovery Bay trap fishery in March 1991 by the Fisheries Improvement Program (FIP) of the University of the West Indies (UWI), whereby active fishers were given large mesh [1.5 inch $(3.8 \mathrm{~cm})]$ wire to construct traps in exchange for handing in their small mesh $[1$ inch $(2.5 \mathrm{~cm})$ and 1.25 inch $(3.2 \mathrm{~cm})]$ traps (see Sary et al. 1991 and Woodley 1994 for details of the program).

Data collection. Most catch and effort data were collected in 3 representative 6 mo periods (July to December) in 1990 (10 mo before the implementation of the mesh exchange program), in 1991 (immediately after the implementation of the mesh exchange program) and in 1994 ( $3 \mathrm{yr}$ after the implementation of the mesh exchange program). In the July to December periods of 1990 and 1991, catch and effort data were collected at the 2 fish landing beaches in Discovery Bay (Fig. 1) once a week, on randomly selected days. On these sampling days, all the catches landed at a site by consenting fishers were sorted to species, counted and 

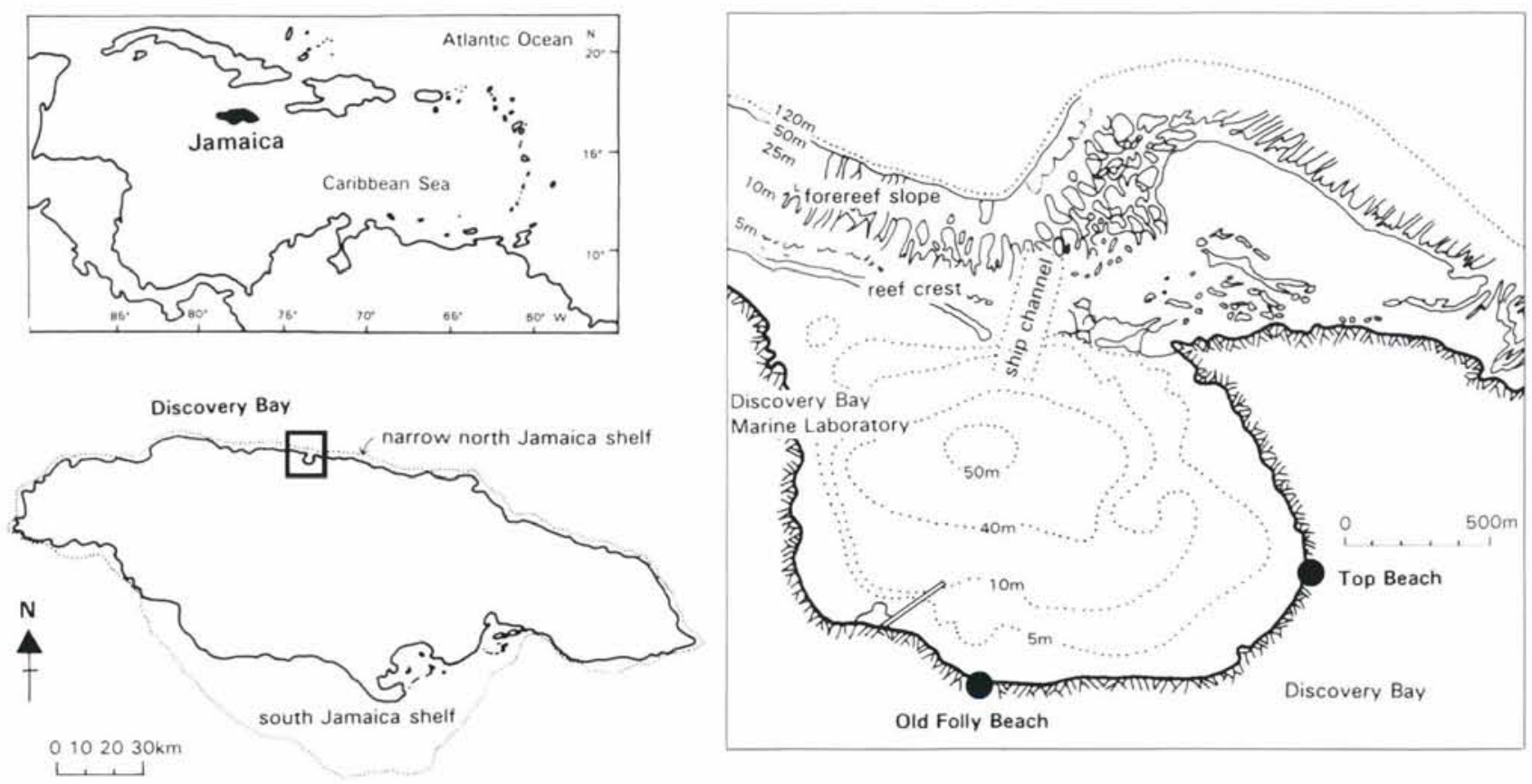

Fig. 1. Map of Jamaica showing the extent of the island shelf and the location of the study area, Discovery Bay. Also shown are geographical position of Jamaica in the Caribbean and topography of Discovery Bay showing reef outlines and location of the 2 main fish landing sites ( ) (adapted from Woodley \& Robinson 1977)

weighed to the nearest $0.01 \mathrm{~kg}$. Information on the number of traps hauled, average soak time and mesh size of each fishtrap was also collected concurrently from the fishers wherever possible. From July to December 1994, catch and effort data were collected directly (once or twice a week) from a subsample of 13 cooperative $(38 \%$ of all) Discovery Bay trap fishers operating from both landing sites. During this period of data collection, the catch from each mesh size was kept separate by the fishers and was further sorted to species, counted and weighed to the nearest $0.01 \mathrm{~kg}$. Information on the number of traps of each mesh size hauled and the soak times was also collected concurrently from the fishers.

The total number of traps of various mesh sizes in use in the Discovery Bay trap fishery, before (1990) and immediately after (1991) the implementation of the mesh exchange program, was estimated by observation and from interviews with fishers as reported in Sary et al. (1991). The total number of traps of each mesh size in use $3 \mathrm{yr}$ after (1994) the implementation of the mesh exchange program was estimated by a formal survey of all active trap fishers in Discovery Bay, conducted between October and December 1994.

The total number of traps hauled per month (from March 1990 to October 1992) was estimated by extrapolation of data collected at the 2 fish landing beaches once a week, on randomly selected days. On these sampling days the total number of trap fishers going to sea was noted and the total number of traps hauled by each fisher sampled was recorded.

Fork lengths (FL) of all individuals of the 2 most common species encountered in the sampled catches of both small mesh and large mesh traps, redband parrotfish Sparisoma aurofrenatum and ocean surgeon Acanthurus bahianus, were measured to the nearest $1 \mathrm{~mm}$ in four 6 mo (July to December) sampling periods (i.e. in 1990, 1991, 1992 and 1994).

Data analyses. Changes in finfish catch per haul (i.e. CPUE as number of fish per trap per haul and $\mathrm{kg}$ per trap per haul) for both 1.25 and 1.5 inch traps were examined by comparing the CPUE of all fishers sampled in each of the 3 separate 6 mo periods (July to December) in 1990, 1991 and 1994. The data did not follow a normal distribution, and thus non-parametric analyses of variance were used to compare CPUE among years for 1.25 inch mesh traps and for 1.5 inch mesh traps. Differences in CPUE were first tested with the Kruskal-Wallis non-parametric ANOVA; if a significant difference was found, 2 years were compared at a time using the Mann-Whitney U-test.

Changes in finfish species composition of fishtrap catches were examined by comparing CPUE (as kg fish per trap per haul) at the family level in the three 6 mo periods (July to December) in 1990, 1991 and 1994. Family groupings followed those of Koslow et al. (1988) except for the Miscellaneous group (MIX) which here included the families Sciaenidae, Chaetodonti- 
dae, and Pomacanthidae (for which there were very few representatives), as well as others not included in any fish group by Koslow et al. (1988). A complete list of all species within each group is given by Sary (1995). The CPUE data did not follow a normal distribution. Therefore, CPUE of each fish group was compared between years using Mann-Whitney $U$-tests for 1.25 inch mesh traps and for 1.5 inch mesh traps.

Mean weight of individual finfish caught was calculated from available data on the number and weight of finfish per trap, for the three 6 mo periods (July to December) in 1990, 1991 and 1994. The data did not follow a normal distribution, and thus non-parametric analyses of variance were used to compare fish weight among years for 1.25 inch mesh traps and for 1.5 inch mesh traps. Differences in fish weight were first tested with the Kruskal-Wallis non-parametric ANOVA; when a significant difference was found, 2 years were compared at a time using the MannWhitney $U$-test.

Changes in the population size structure of the 2 most common species in the trap catches, the redband parrotfish Sparisoma aurofrenatum and the ocean surgeon Acanthurus bahianus were examined by comparing mean FLs in the four 6 mo periods (July to December) in 1990 (10 mo before the implementation of the mesh exchange program), 1991 (immediately after the implementation of the mesh exchange program), 1992 (1 yr after the implementation of the mesh exchange program), and 1994 (3 yr after the implementation of the mesh exchange program). The data followed a normal distribution, and thus parametric ANOVA was used to compare mean sizes among sampling periods for 1.25 inch mesh traps and for 1.5 inch mesh traps.

Changes in fishing effort as a result of the mesh exchange program were examined by comparing the annual mean number of trap hauls per month (data were available from March 1990 to October 1992) between 1990 (the year before the mesh exchange program was implemented), 1991 (the year the mesh exchange program was implemented) and 1992 (the year after the mesh exchange program was implemented). The data followed a normal distribution and thus a parametric ANOVA was used to compare means among years for all mesh size traps in the fishery.

Changes in soak time of traps (in days) were examined by comparing the reported soak time of traps of all fishers sampled in each of 3 separate 6 mo periods (July to December) in the years 1990, 1991 and 1994. The data did not follow a normal distribution, and thus Kruskal-Wallis non-parametric ANOVA was used to compare soak time among years for 1.25 inch mesh traps and for 1.5 inch mesh traps.

\section{RESULTS}

\section{Changes in fishing pressure}

The total number of fishtraps being used in the Discovery Bay trap fishery did not appear to change substantially as a result of the mesh exchange program. There were approximately 324 in use immediately before and 325 in use immediately after the implementation of the mesh exchange program (Sary et al. 1991), and $3 \mathrm{yr}$ after the program was implemented, the number of traps in the fishery changed only slightly (to approximately 285). Likewise, mean number of trap hauls per month did not vary significantly between 1990 (107 hauls per month), 1991 (127 hauls per month), and 1992 (149 hauls per month) (ANOVA: $F=$ 1.352, $\mathrm{n}=32, \mathrm{p}=0.274)$. Furthermore, soak time, although different for the large and small mesh traps, did not change as a result of the mesh exchange program (Table 1; for 1.25 inch mesh traps, Kruskal-Wallis test: $H=1.23, \mathrm{n}=311, \mathrm{p}=0.541 ;$ for 1.5 inch mesh traps, Mann Whitney test: $U=1400, \mathrm{n}=123, \mathrm{p}=0.156$ ).

However, the proportions of small mesh traps changed substantially from $94 \%$ (1 inch mesh: 68; 1.25 inch mesh: 236; 1.5 inch mesh: 20$)$ in 1990 (10 mo before the implementation of the mesh exchange program) to $32 \%$ (1 inch mesh: $4 ; 1.25$ inch mesh: 99 ; 1.5 inch mesh: 222) in 1991 (immediately after the implementation of the mesh exchange program) and to $58 \%$ ( 1 inch mesh: $10 ; 1.25$ inch mesh: $155 ; 1.5$ inch mesh: 120) in 1994 ( 3 yr after the implementation of the mesh exchange program).

Table 1. Fishing pressure in the Discovery Bay trap fishery shown as total number of traps, relative abundance of small mesh traps, and mean soak times in days for 1.25 inch mesh fishtraps and for 1.5 inch mesh fishtraps from July to December in 1990 , 1991 and 1994. n: number of traps sampled

\begin{tabular}{|c|c|c|c|c|c|c|}
\hline \multirow[t]{2}{*}{ Year } & \multirow{2}{*}{$\begin{array}{l}\text { Total no. } \\
\text { of fishtraps }\end{array}$} & \multirow{2}{*}{$\begin{array}{l}\text { Relative abundance of } \\
\text { small mesh fishtraps }(\%)\end{array}$} & \multicolumn{2}{|c|}{1.25 inch mesh fishtraps } & \multicolumn{2}{|c|}{1.5 inch mesh fishtraps } \\
\hline & & & $\mathrm{n}$ & Soak time (d) & $\mathrm{n}$ & Soak time (d) \\
\hline 1990 & 324 & 94 & 835 & 3.1 & & \\
\hline 1991 & 325 & 32 & 276 & 3.5 & 201 & 6.0 \\
\hline 1994 & 285 & 58 & 360 & 2.6 & 411 & 4.8 \\
\hline
\end{tabular}




\section{Changes in catch per unit effort (CPUE)}

A total of 1322 catches from 1.25 inch mesh fishtraps and 644 catches from 1.5 inch mesh fishtraps were examined altogether.

\section{Catch per haul of 1.25 inch mesh fishtraps}

Mean catch weight per haul (as kg per trap per haul) for 1.25 inch mesh traps in 1990, 1991, and 1994 is given in Table 2a. Catch weight per haul showed significant variation among years (Kruskal-Wallis test: $H=13.819, \mathrm{n}=326, \mathrm{p}=0.001)$. All 2-sample tests also indicated significant differences in catch weight per haul between years. Catch weight per haul in 1990 was significantly higher than in 1991 (Mann-Whitney test: $U=5604.5, \mathrm{n}=208, \mathrm{p}=0.030$ ). Catch weight per haul in 1994 was significantly higher than in both the earlier years (Mann-Whitney tests: for 1990 vs 1994, $U=7071.5, \mathrm{n}=259, \mathrm{p}=0.038$; for 1991 vs $1994, U=$ 2692, $\mathrm{n}=185, \mathrm{p}<0.001)$.

Mean catch number per haul (as fish per trap per haul) for 1.25 inch mesh traps in 1990, 1991, and 1994 is given in Table 2b. Catch number per haul showed significant variation among years (Kruskal-Wallis test: $H=14.894, \mathrm{n}=290, \mathrm{p}=0.001$ ). However, 2-sample tests indicated that there was no difference in catch number per haul between 1990 and 1991 (Mann-Whitney test: $U=3524, \mathrm{n}=172, \mathrm{p}=0.178$ ), but that catch number per haul in 1994 was significantly higher than in both the earlier years (Mann-Whitney tests: for 1990 vs $1994, U=5430, \mathrm{n}=238, \mathrm{p}=0.002$; for 1991 vs 1994 , $U=2126, \mathrm{n}=170, \mathrm{p}<0.001)$.

In summary, the catch per haul of 1.25 inch traps, after an initial decline, has shown a significant increase from 1990 to 1994 (23\% by weight and $42 \%$ by number) with the implementation of the mesh exchange program.

\section{Catch per haul of 1.5 inch mesh fishtraps}

Mean catch weight per haul (as kg per trap per haul) for 1.5 inch mesh traps in 1991 and 1994 is given in Table 2a. Catch weight per haul showed no significant difference between 1991 and 1994 (Mann-Whitney test: $U=1818, \mathrm{n}=136, \mathrm{p}=0.181$ ).

Mean catch number per haul (as fish per trap per haul) for 1.5 inch mesh traps in 1991 and 1994 is given in Table $2 \mathrm{~b}$. Catch number per haul was significantly higher in 1994 than in 1991 (Mann-Whitney test: $U=$ 1438.5, $\mathrm{n}=131, \mathrm{p}=0.026$ ).

In summary, the catch per haul of 1.5 inch traps has shown a significant increase from 1991 to 1994 in the
Table 2. Mean catch per haul for 1.25 inch and for 1.5 inch mesh fishtraps in the Discovery Bay trap fishery from July to December in 1990, 1991 and 1994. Catches are shown by (a) fish weight in $\mathrm{kg}$, and (b) fish number. $\mathrm{n}$ : number of fishtraps sampled

\begin{tabular}{|c|c|c|c|c|}
\hline \multicolumn{5}{|c|}{ (a) kg per trap per haul } \\
\hline \multirow[t]{2}{*}{ Year } & \multicolumn{2}{|c|}{1.25 inch mesh fishtraps } & \multicolumn{2}{|c|}{1.5 inch mesh fishtraps } \\
\hline & $\mathrm{n}$ & $\mathrm{kg}$ & $\mathrm{n}$ & $\mathrm{kg}$ \\
\hline 1990 & 590 & 0.79 & & \\
\hline 1991 & 207 & 0.60 & 176 & 0.83 \\
\hline 1994 & 367 & 1.03 & 444 & 1.24 \\
\hline \multicolumn{5}{|c|}{ (b) No. of fish per trap per haul } \\
\hline \multirow[t]{2}{*}{ Year } & 1.25 inch & esh fishtraps & \multirow{2}{*}{\multicolumn{2}{|c|}{$\begin{array}{c}1.5 \text { inch mesh fishtraps } \\
n \text { no. fish }\end{array}$}} \\
\hline & $\mathrm{n}$ & no. fish & & \\
\hline 1990 & 721 & 5.9 & & \\
\hline 1991 & 234 & 5.2 & 200 & 4.0 \\
\hline 1994 & 367 & 8.5 & 444 & 6.0 \\
\hline
\end{tabular}

number of fish per haul $(50 \%)$ with the implementation of the mesh exchange program. The corresponding increase in weight per haul $(43 \%)$, however, was not significant.

\section{Catch per unit time for all fishtraps}

Estimated weekly catches in the Discovery Bay fishery for 1 inch (data from Sary 1995), 1.25 inch and 1.5 inch mesh traps and total weekly catch by all traps are given in Table 3. In 1990 the catch per week by 1 inch traps was very similar to that by 1.25 inch traps, while in later years the samples are too small for changes to be considered. The 1.25 inch traps show a reduced catch per week in 1991, but a considerable increase in 1994. Catch per week by 1.5 inch traps (on which no data are available for 1990) also apparently increased considerably between 1991 and 1994. Overall, there was a marked reduction $(-38 \%)$ in total trap catch per week in 1991 and a substantial increase by 1994 to a level $15 \%$ greater than in 1990 .

\section{Changes in catch composition}

\subsection{5 inch mesh fishtraps}

The mean catch composition of 1164 traps of 1.25 inch mesh (as $\mathrm{kg}$ per trap per haul by family groups) in 1990, 1991 and 1994 is given in Table 4. Catch composition differed significantly among all years (Pearson $3 \times 13$ chi-square contingency test: $\chi^{2}=$ 289.7. $\mathrm{p}<0.001$ ) and between all pairs of years (Pearson $2 \times 13$ chi-square contingency test: for 1990 vs 
Table 3. Estimated weekly catch (kg) for the Discovery Bay trap fishery, shown separately for each mesh size trap in use from July to December in 1990,1991 and 1994 , and as a gross weekly total across all traps

\begin{tabular}{|c|c|c|c|c|c|c|c|}
\hline Trap type & Year & $\begin{array}{l}\text { Soak time } \\
\text { (d) }\end{array}$ & $\begin{array}{c}\text { No. of } \\
\text { hauls wk }{ }^{-1}\end{array}$ & $\begin{array}{l}\text { Catch per } \\
\text { haul }(\mathrm{kg})\end{array}$ & $\begin{array}{c}\text { Catch wk }{ }^{-1} \\
(\mathrm{~kg})\end{array}$ & $\begin{array}{l}\text { Total no. of } \\
\text { traps }(\mathrm{kg})\end{array}$ & $\begin{array}{c}\text { Total catch } \\
\mathrm{wk}^{-1}\end{array}$ \\
\hline 1 inch mesh & $\begin{array}{l}1990 \\
1991 \\
1994\end{array}$ & $\begin{array}{l}2.9 \\
3.6 \\
2.6\end{array}$ & $\begin{array}{l}2.41 \\
1.94 \\
2.69\end{array}$ & $\begin{array}{l}0.69 \\
1.40 \\
0.77\end{array}$ & $\begin{array}{l}1.66 \\
2.72 \\
2.07\end{array}$ & $\begin{array}{r}68 \\
4 \\
10\end{array}$ & $\begin{array}{r}113 \\
11 \\
21\end{array}$ \\
\hline 1.25 inch mesh & $\begin{array}{l}1990 \\
1991 \\
1994\end{array}$ & $\begin{array}{l}3.1 \\
3.5 \\
2.6\end{array}$ & $\begin{array}{l}2.26 \\
2.00 \\
2.69\end{array}$ & $\begin{array}{l}0.79 \\
0.60 \\
0.97\end{array}$ & $\begin{array}{l}1.78 \\
1.20 \\
2.61\end{array}$ & $\begin{array}{r}236 \\
99 \\
155\end{array}$ & $\begin{array}{l}421 \\
119 \\
405\end{array}$ \\
\hline 1.5 inch mesh & $\begin{array}{l}1990 \\
1991 \\
1994\end{array}$ & $\begin{array}{l}- \\
6.0 \\
4.8\end{array}$ & $\begin{array}{l}\overline{1.17} \\
1.46\end{array}$ & $\begin{array}{l}-\overline{83} \\
1.19\end{array}$ & $\begin{array}{l}-\overline{97} \\
1.74\end{array}$ & $\begin{array}{r}20 \\
222 \\
120\end{array}$ & $\begin{array}{l}19^{a} \\
215 \\
208\end{array}$ \\
\hline All meshes & $\begin{array}{l}1990 \\
1991 \\
1994\end{array}$ & & & & & $\begin{array}{l}324 \\
325 \\
285\end{array}$ & $\begin{array}{l}553 \\
345 \\
634\end{array}$ \\
\hline
\end{tabular}

$1991, \chi^{2}=126.9, \mathrm{p}<0.001 ;$ for 1990 vs $1994, \chi^{2}=168.0$, $\mathrm{p}<0.001$; for 1991 vs $\left.1994, \chi^{2}=68.6, \mathrm{p}<0.001\right)$. Over all years, small parrotfish (SSC), surgeonfish (ACN), squirrelfish (HOL), snappers (LUT) and the miscellaneous fish (MIX) were the most important groups (Table 4). However, their relative importance (as shown by rank in Table 4) varied between years.

The percent difference in catch per haul of each fish group between pairs of years is shown in Fig. 2. Between 1990 and 1991, only the small groupers (SSR) showed a large increase in abundance (Fig. 2a), but the change was not significant (Mann-Whitney test: $U=1897, \mathrm{n}=143, \mathrm{p}=0.221)$. Most groups (9 of the 13) showed decreases in abundance (Fig. 2a), although only the decreases in the groups HOL and puffers/boxfish (TET) were significant (Mann-Whitney tests: for HOL, $U=2970, \mathrm{n}=143, \mathrm{p}<0.001$; for TET, $U=2442$, $\mathrm{n}=143, \mathrm{p}=0.022$ ).

Between 1990 and 1994, most groups (8 of the 13) showed increases in abundance (Fig. 2b), and the increases in the groups SSC, grunts (HAM), SSR and MIX were significant (Mann-Whitney tests: for SSC, $U=4265, \mathrm{n}=217, \mathrm{p}=0.001 ;$ for HAM, $U=6921, \mathrm{n}=$ 217, $\mathrm{p}=0.015$; for SSR, $U=4533, \mathrm{n}=217, \mathrm{p}=0.002$; for MIX, $U=6743, \mathrm{n}=217, \mathrm{p}=0.037$ ). On the other hand, significant decreases in abundance (Fig. 2b) occurred in the groups TET, large parrotfish (LSC), and $\mathrm{ACN}$ (Mann-Whitney tests: for TET, $U=6368, \mathrm{n}=217, \mathrm{p}=$

Table 4. Catch composition (as mean kg per trap per haul for each fish group) of 1.25 inch and 1.5 inch mesh fishtraps in the Discovery Bay trap fishery from July to December in 1990, 1991 and 1994 . Numbers in parentheses represent fish group ranks. SSC: small Scaridae; LSC: large Scaridae; ACN: Acanthuridae; HAM: Haemulidae; HOL: Holocentridae; LUT: Lutjanidae; SSR: small Serranidae; LSR: large Serranidae; MUL: Mullidae; CAR: Carangidae; BAL: Balistidae and Monacanthidae; TET: other tetraodontiformes; MIX: miscellaneous

\begin{tabular}{|c|c|c|c|c|c|c|c|c|c|c|}
\hline \multirow{3}{*}{$\begin{array}{l}\text { Family } \\
\text { code }\end{array}$} & \multicolumn{6}{|c|}{1.25 inch mesh fishtraps } & \multicolumn{4}{|c|}{1.5 inch mesh fishtraps } \\
\hline & \multicolumn{2}{|c|}{$1990(\mathrm{n}=590)$} & \multicolumn{2}{|c|}{$1991(\mathrm{n}=207)$} & \multicolumn{2}{|c|}{$1994(\mathrm{n}=367)$} & \multicolumn{2}{|c|}{$1991(n=176)$} & \multicolumn{2}{|c|}{$1994(n=444$} \\
\hline & $\mathrm{kg}$ & Rank & $\mathrm{kg}$ & Rank & $\mathrm{kg}$ & Rank & $\mathrm{kg}$ & Rank & $\mathrm{kg}$ & Rank \\
\hline SSC & 0.22 & (1) & 0.24 & (1) & 0.36 & (1) & 0.20 & (1) & 0.05 & (6) \\
\hline LSC & 0.06 & (5) & 0.03 & (6) & 0.03 & (9) & 0.09 & (4) & 0.10 & (4) \\
\hline $\mathrm{ACN}$ & 0.12 & (2) & 0.10 & (2) & 0.11 & (3) & 0.16 & (2) & 0.44 & (1) \\
\hline HAM & 0.04 & (9) & 0.04 & (5) & 0.05 & (8) & 0.05 & (6) & 0.24 & $(2)$ \\
\hline $\mathrm{HOL}$ & 0.07 & (3) & 0.03 & (7) & 0.08 & (4) & 0.02 & (9) & 0.03 & (7) \\
\hline LUT & 0.03 & (10) & 0.02 & (9) & 0.11 & (2) & 0.16 & (3) & 0.14 & (3) \\
\hline SSR & 0.02 & (12) & 0.05 & (4) & 0.06 & (6) & 0.00 & (11) & 0.01 & (11) \\
\hline LSR & 0.04 & (7) & 0.00 & (13) & 0.00 & (13) & 0.00 & (13) & 0.00 & (13) \\
\hline MUL & 0.06 & (6) & 0.02 & (8) & 0.06 & (5) & 0.01 & (10) & 0.01 & (12) \\
\hline CAR & 0.00 & (13) & 0.00 & (12) & 0.02 & (11) & 0.05 & (5) & 0.07 & (5) \\
\hline BAL & 0.03 & (11) & 0.01 & (10) & 0.02 & (10) & 0.03 & (8) & 0.03 & (9) \\
\hline TET & 0.07 & (4) & 0.00 & (11) & 0.02 & (12) & 0.00 & (12) & 0.02 & (10) \\
\hline MIX & 0.04 & (8) & 0.05 & (3) & 0.06 & (7) & 0.05 & (7) & 0.03 & (8) \\
\hline
\end{tabular}


(a) Percent change between 1990 and 1991

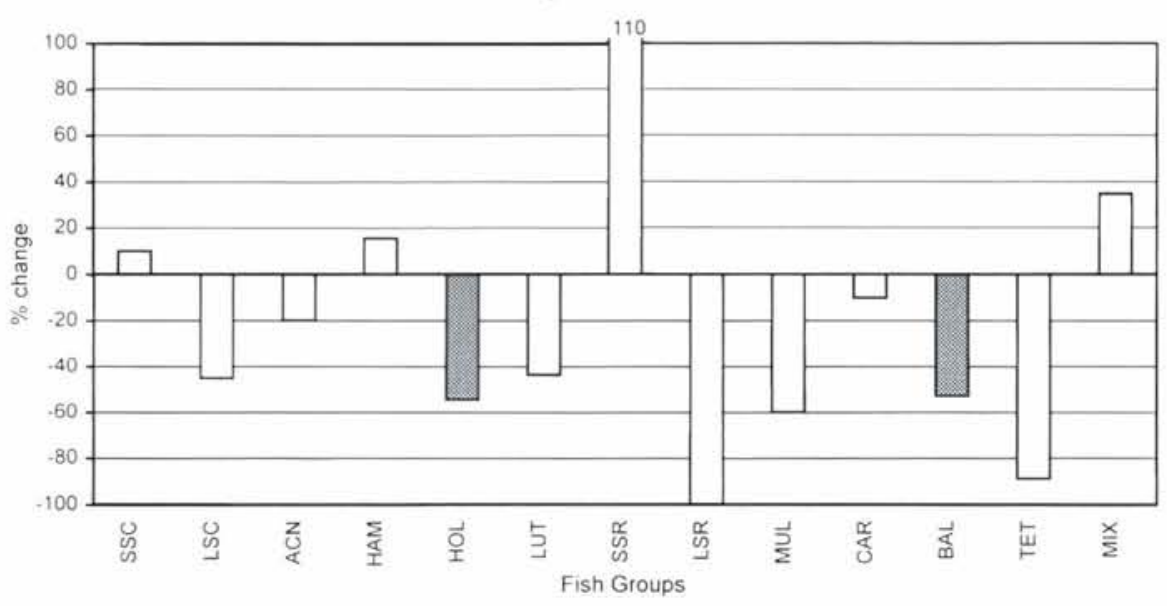

Fig. 2. Percent change in catch composition (as mean $\mathrm{kg}$ per trap per haul for each fish group) of 1.25 inch mesh fishtraps in the Discovery Bay trap fishery (a) between 1990 (July to December) and 1991 (July to December), and (b) between 1990 (July to December) and 1994 (July to December). Shading indicates significant changes (Mann-Whitney tests, p < 0.05). SSC: small Scaridae; LSC: large Scaridae; ACN: Acanthuridae; HAM: Haemulidae; HOL: Holocentridae; LUT: Lutjanidae; SSR: small Serranidae; LSR: large Serranidae; MUL: Mullidae; CAR: Carangidae; BAL: Balistidae and Monacanthidae; TET: other tetraodontiformes; MIX: miscellaneous

0.037; for LSC, $U=6808, \mathrm{n}=217, \mathrm{p}=0.025$; for $\mathrm{ACN}$, $U=7250, \mathrm{n}=217, \mathrm{p}=0.002$ ).

\section{5 inch mesh fishtraps}

The mean catch composition of 620 traps of 1.5 inch mesh (as kg per trap per haul by family groups) in 1991 and 1994 is given in Table 4. Catch composition differed significantly between the 2 years (Pearson $2 \times 13$ chisquare contingency test: $\chi^{2}=327.9, \mathrm{p}<0.001$ ). Over all years, ACN, LUT, SSC, and HAM were the most important groups (Table 4). However, their relative importance (as shown by rank in Table 4) varied between years.

The percent difference in catch per haul of each fish group between 1991 and 1994 is shown in Fig. 3. Most groups (9 of the 13) showed increases in relative abundance (Fig. 3). However, only for ACN was the increase significant (Mann-Whitney test: $U=1324, \mathrm{n}=$ $131, \mathrm{p}=0.017$ ). The group SSC was the only one showing a significant decrease (Mann-Whitney test: $U=$ 2226, $\mathrm{n}=131, \mathrm{p}=0.015)$. (b) Percent change between 1990 and 1994

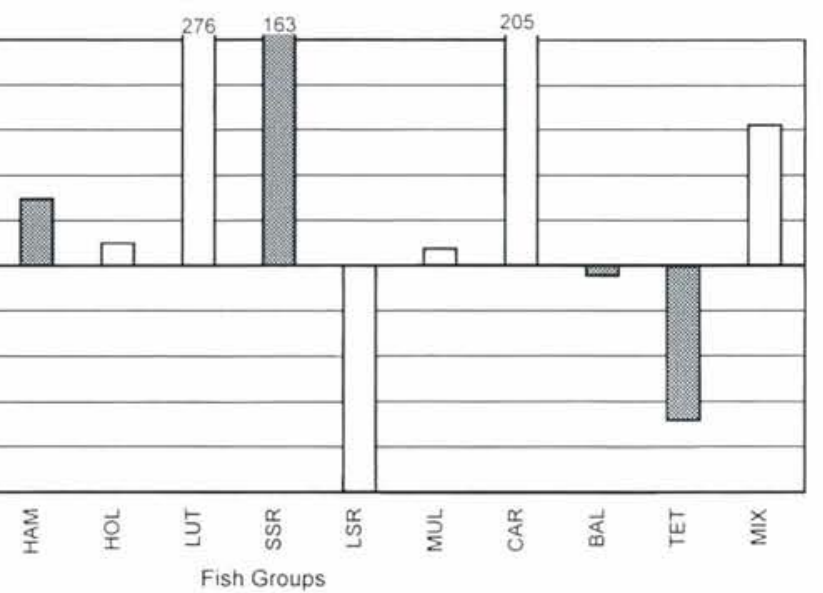

Mean individual fish weight in 1.25 inch mesh traps in 1990, 1991 and 1994 is given in Table 5. Individual fish weight showed no significant variation among years (Kruskal-Wallis test: $H=3.39, \mathrm{n}=288, \mathrm{p}=0.183$ ).

Mean individual fish weight in 1.5 inch mesh traps in 1991 and 1994 is given in Table 5. Individual fish weight was significantly higher in 1991 than in 1994 (Mann-Whitney test: $U=2412, \mathrm{n}=132, \mathrm{p}=0.022$ ).

Table 5. Mean weight $(\mathrm{kg})$ of individual fish taken by $1.25 \mathrm{inch}$ mesh fishtraps and by 1.5 inch mesh fishtraps in the Discovery Bay trap fishery from July to December in 1990, 1991 and 1994. n: number of traps sampled

\begin{tabular}{|ccccc|}
\hline Year & \multicolumn{3}{c}{$\begin{array}{c}1.25 \\
\text { inch mesh fishtraps }\end{array}$} & \multicolumn{3}{c|}{$\begin{array}{c}\text { inch mesh fishtraps } \\
\mathrm{n}\end{array}$} & $\mathrm{kg}$ & $\mathrm{kg}$ \\
\hline 1990 & 712 & 0.12 & & \\
1991 & 218 & 0.13 & 189 & 0.24 \\
1994 & 367 & 0.12 & 444 & 0.20 \\
\hline
\end{tabular}




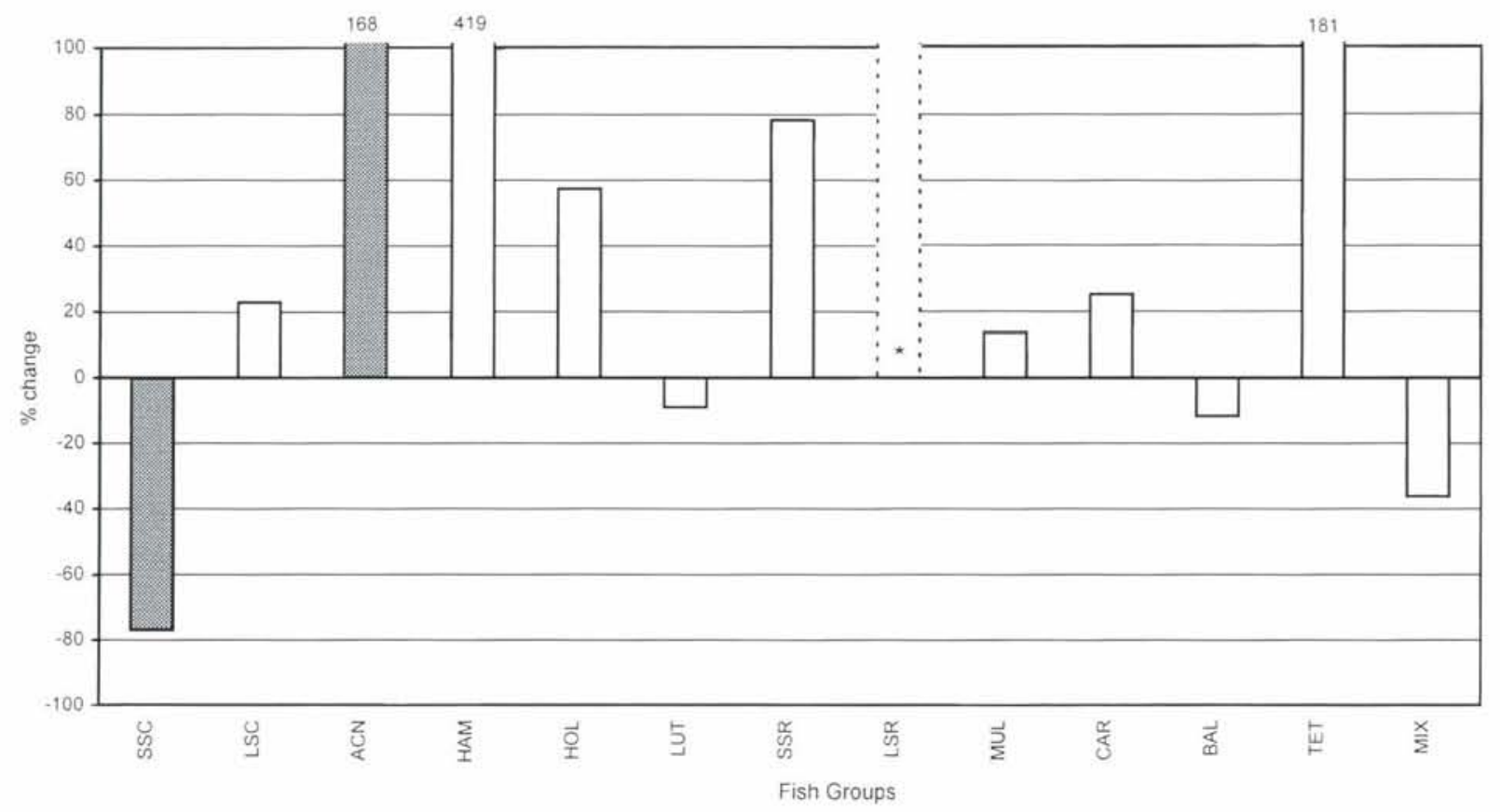

Fig. 3. Percent change in catch composition (as mean kg per trap per haul for each fish group) of 1.5 inch mesh fishtraps in the Discovery Bay trap fishery between 1991 (July to December) and 1994 (July to December). Shading indicates significant changes (Mann-Whitney tests, $\mathrm{p}<0.05$ ). Abbreviations as in Fig. 2. $\left(^{\star}\right) \%$ change is infinite (i.e. from 0 to $0.01 \mathrm{~kg}^{\text {trap }}$ ( haul $^{-1}$, but not significant

\section{Changes in length-irequency distribution of 2 common species}

Redband parrotfish

Mean lengths of 1952 redband parrotfish taken by 1.25 inch mesh traps in 1990, 1991, 1992 and 1994 are given in Table 6 and the length-frequency distributions are given in Fig. 4a. Mean lengths showed significant differences among years (ANOVA: $F=49.556$, $\mathrm{n}=1952, \mathrm{p}<0.001$ ). Results of Tukey's multiple range test showed that mean sizes in 1990 and 1991 were

Table 6. Sparisoma aurofrenatum. Mean size [fork length (FL) in $\mathrm{mm}$ | of redband parrotfish caught in 1.25 inch and 1.5 inch mesh fishtraps from July to December in 1990, 1991, 1992 and 1994. $\mathrm{n}$ : number of fish in sample; 'in same column indicates no significant difference between years (Tukey's multiple range test, $\mathrm{p}>0.05$ )

\begin{tabular}{|c|c|c|c|c|c|c|c|}
\hline Year & \multicolumn{4}{|c|}{$\begin{array}{l}1.25 \text { inch mesh fishtraps } \\
n \quad F L(m m)\end{array}$} & \multicolumn{3}{|c|}{1.5 inch mesh fishtraps } \\
\hline 1990 & 484 & 161.4 & $(14.66)^{\circ}$ & & 0 & - & - \\
\hline 1991 & 211 & 161.9 & $(13.07)^{\circ}$ & & 79 & 178.8 & $(15.82)^{\circ}$ \\
\hline 1992 & 216 & 172.5 & $(15.28)$ & - & 50 & 188.1 & $(15.66)$ \\
\hline 1994 & 1041 & 170.0 & $(16.81)$ & $\cdot$ & 52 & 177.5 & $(22.74)^{\circ}$ \\
\hline
\end{tabular}

similar to one another, but significantly smaller than the mean sizes in 1992 and 1994 (Table 6, Fig. 4a).

Mean lengths of 181 redband parrotfish taken by 1.5 inch mesh traps in 1991, 1992 and 1994 are given in Table 6 and the length-frequency distributions are given in Fig. 4b. Mean lengths showed significant differences between years (ANOVA: $F=5.365, \mathrm{n}=181$, $\mathrm{p}<0.001)$. Results of Tukey's multiple range test showed that mean lengths in 1991 and 1994 are similar and significantly smaller than the mean size in 1992 (Table 6, Fig. 4b).

\section{Ocean surgeon}

Mean lengths of 995 ocean surgeon taken by 1.25 inch mesh traps in 1990,1991, 1992 and 1994 are given in Table 7 and the length-frequency distributions are given in Fig. 5a. Mean lengths showed significant differences between years (ANOVA: $F=6.136, n$ $=995, p<0.001)$. Results of Tukey's multiple range test showed that mean sizes in 1990, 1991 and 1994 are similar and significantly larger than the mean size in 1992 (Table 7. Fig. 5a).

Mean lengths of 1414 ocean surgeons caught in 1.5 inch mesh traps in 1991, 1992 and 1994 are given in Table 7 and the length-frequency distributions are 
given in Fig. 5b. Mean lengths showed significant differences between years (ANOVA: $F=27.903, \mathrm{n}=1414, \mathrm{p}<$ 0.001). Results of Tukey's multiple range test showed that mean sizes in 1991 and 1994 are similar and significantly larger than the mean size in 1992 (Table 7, Fig. 5b).

\section{DISCUSSION}

\section{Reduction in fishing pressure}

The north coast of Jamaica is considered one of the most overfished reef areas in the Caribbean (Government of Jamaica 1994, Hughes 1994) primarily because of the heavy fishing pressure exerted on juvenile fish by a large number of small mesh traps fishing along the narrow island shelf (Sandeman \& Woodley 1994). This study observed the effects of reducing fishing pressure on the overexploited reef fish community at Discovery Bay, on the north coast of Jamaica, by increasing the average trap mesh size in the trap fishery there.

Although the total number of active traps and the total number of hauls per month did not significantly change in the Discovery Bay fishery during the study period (1990 to 1994), the proportion of small mesh traps decreased substantially as a result of the Fisheries Improvement Project's mesh exchange program, implemented in 1991. Presumably, a concurrent reduction of fishing mortality in smaller fish occurred. (a)

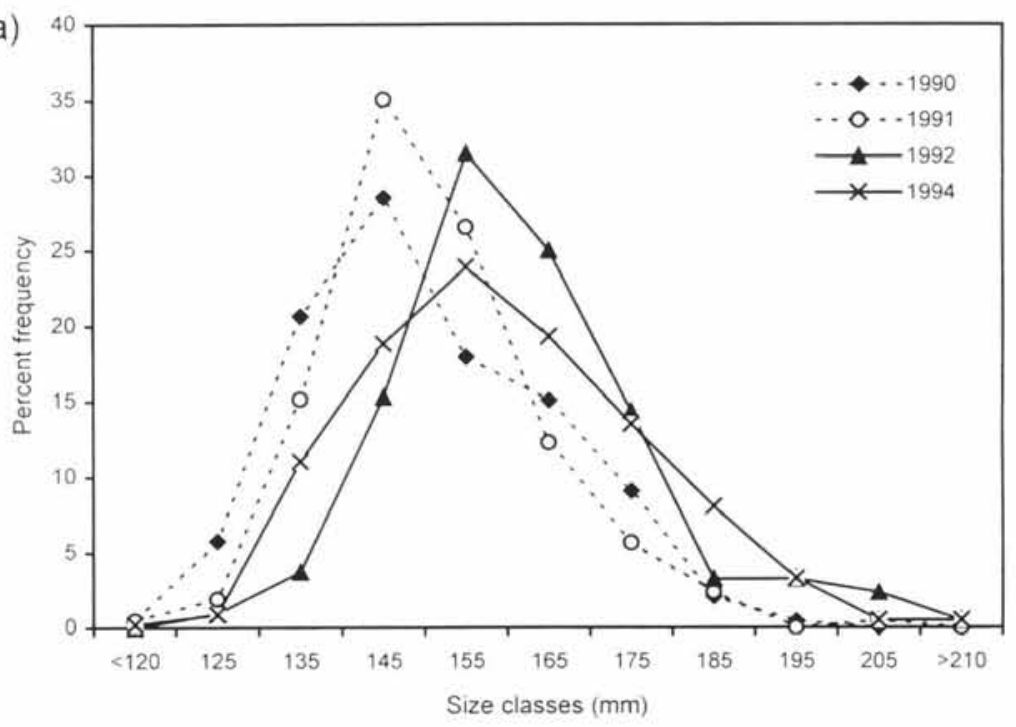

(b)

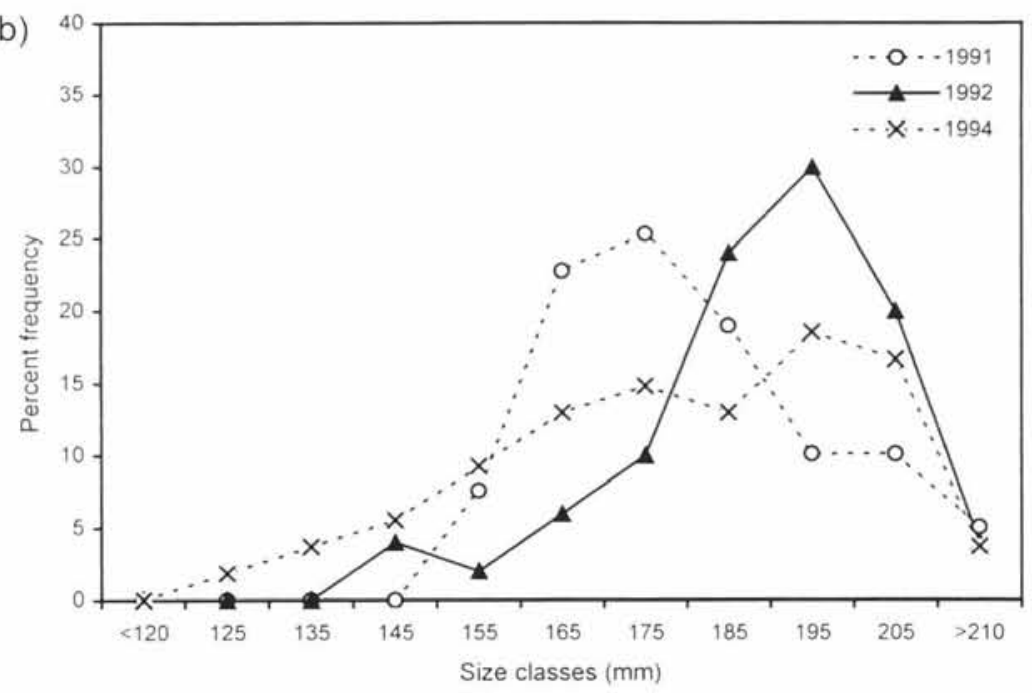

Fig. 4. Sparisoma aurofrenatum. Size frequency distribution of redband parrotfish from July to December in 1990, 1991, 1992 and 1994, caught in (a) 1.25 inch mesh fishtraps and (b) 1.5 inch mesh fishtraps. Same style lines (i.e. dashed or solid) indicate that means are not significantly different (ANOVA, $p>0.05$ )
Table 7. Acanthurus bahianus. Mean size [fork length $(\mathrm{FL})$ in $\mathrm{mm}$ ] of ocean surgeon caught in 1.25 inch and 1.5 inch mesh fishtraps from July to December in 1990, 1991, 1992 and 1994. $\mathrm{n}$ : number of fish in sample; 'in same column indicates no significant differences between years (Tukey's multiple range test, $\mathrm{p}>0.05$ )

\begin{tabular}{|c|c|c|c|c|c|c|}
\hline \multirow[t]{2}{*}{ Year } & \multicolumn{3}{|c|}{1.25 inch mesh fishtraps } & \multicolumn{3}{|c|}{1.5 inch mesh fishtraps } \\
\hline & $\mathrm{n}$ & $\mathrm{FL}$ & (SD) & $\mathrm{n}$ & FL & (SD) \\
\hline 1990 & 342 & 146.3 & $(19.74)^{\circ}$ & 0 & - & - \\
\hline 1991 & 193 & 149.3 & $(20.13)^{\circ}$ & 239 & 155.5 & $(17.41)^{*}$ \\
\hline 1992 & 164 & 141.3 & $(18.23)$ & 326 & 149.8 & (16.14) \\
\hline 1994 & 296 & 148.0 & $(17.44)^{\circ}$ & 849 & 157.8 & $(16.38)^{\circ}$ \\
\hline
\end{tabular}

\section{Changes in CPUE and catch composition}

The mesh exchange program appeared to have few significant short-term effects on fish populations at Discovery Bay, but some impact on trap catches in the fishery. During the period immediately after the implementation of the mesh exchange program, the catch per haul of small mesh (1.25 inch) traps dropped significantly in terms of weight $(-24 \%)$, but not numbers. This short-term drop in catches appears to have resulted from many fish groups with large and deepbodied species (e.g. ACN, LSC, LUT) being reduced in the catches of the small mesh traps after the large mesh (1.5 inch) was introduced in the fishery. This 

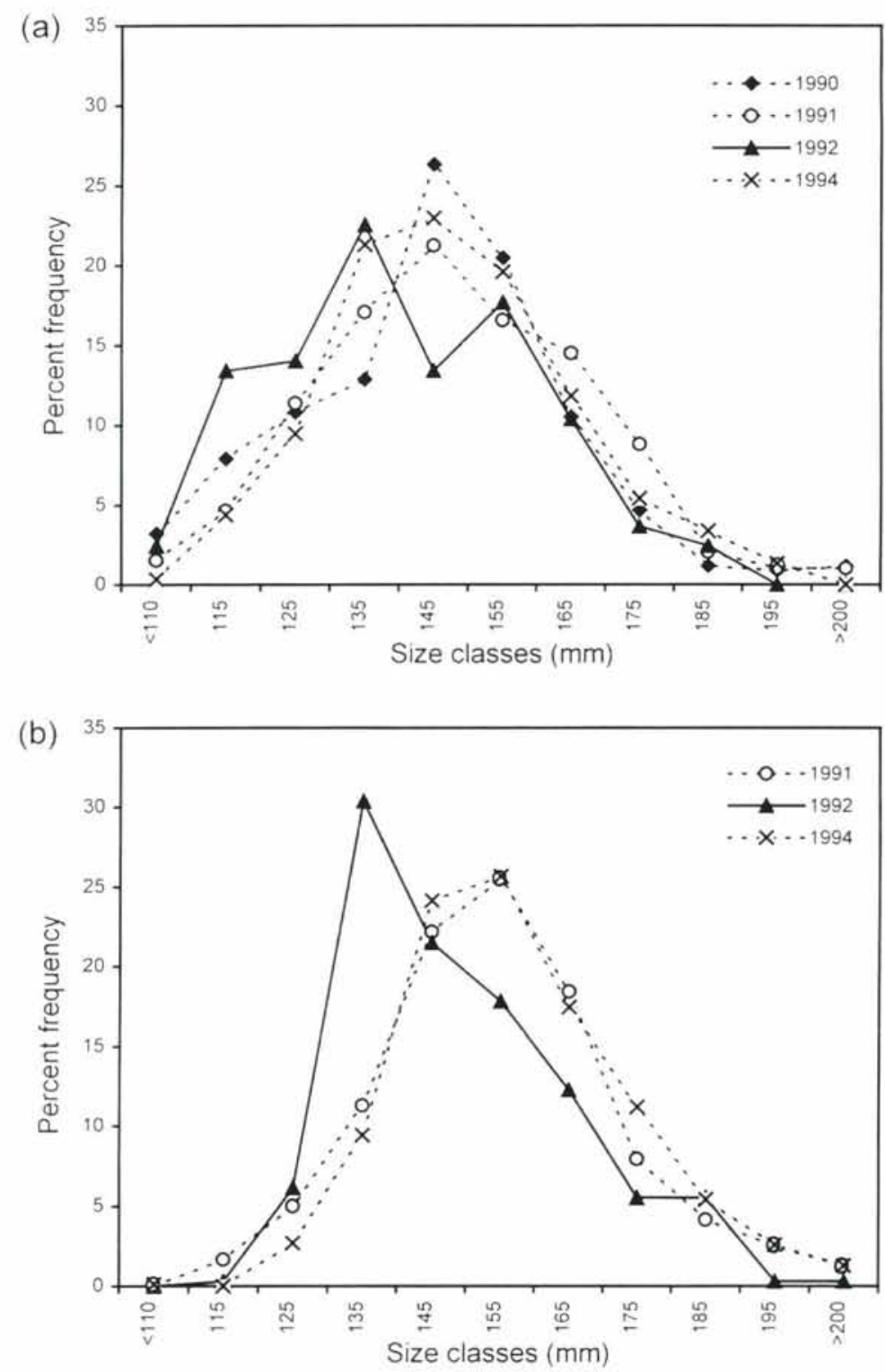

Fig. 5. Acanthurus bahianus. Size frequency distribution of ocean surgeon from July to December in 1990, 1991, 1992 and 1994, caught in (a) 1.25 inch mesh fishtraps and (b) 1.5 inch mesh fishtraps. Same style lines (i.e. dashed or solid) indicate that means are not significantly different (ANOVA, $p>0.05$ )

short-term change in catches was not likely to be caused by changes in the fish population, but perhaps reflects a higher selectivity of large mesh traps than small mesh ones for the large and deep-bodied fish, so that the introduction of the larger mesh traps actually caused a short-term decrease in the catch of the small mesh traps. The varying selectivity of the 2 mesh sizes may have been further enhanced by fishers deliberately targeting large fish with large mesh traps using different trap location, depth, and bait. This result appears to contradict earlier suggestions, at least for some species, that the fishing power of traps decreases with increasing mesh size (Hunte \& Mahon 1994).

However, despite the possible higher selectivity of the large mesh traps for certain species compared with small mesh traps, the overall catch rate (catch per week) of large mesh traps was lower $(0.97 \mathrm{~kg}$ or 4.7 fish per week) than small mesh traps (1.2 kg or 10.4 fish per week) immediately after the implementation of the mesh exchange program, since mean soak time for large mesh traps ( 6 d) was significantly greater than for small mesh traps (3.5 d). This result is consistent with previous field studies which have compared catch rates of traps of different mesh sizes fished concurrently in the same area, and have reported substantially lower catch rates for the larger mesh traps (Hunte \& Mahon 1994). Furthermore, gross catch per week for the trap fishery was greatly reduced (from $553 \mathrm{~kg}$ to $345 \mathrm{~kg}$ per week) immediately after the mesh exchange due to removal of the more efficient small mesh traps.

Long-term effects of the mesh exchange program on fish populations were more pronounced. Catches per haul (as kg per trap per haul and as fish per trap per haul) were significantly higher in the trap fishery $3 \mathrm{yr}$ after the implementation of the mesh exchange program than either before or immediately after. For example, small mesh traps had a mean catch per haul that was significantly higher, $23 \%$ by weight and $42 \%$ by number, in 1994 than in 1990 (before the implementation of the larger mesh program). Large mesh traps also had an increased catch per haul in the $3 \mathrm{yr}$ since they were introduced, in both weight and number of fish, but only the increase in number was significant.

Overall catch rates (catch per week) of small mesh (1.25 inch) and large mesh (1.5 inch) traps had both increased substantially by 1994. Although the catch rate of large mesh traps remained considerably less ( $1.7 \mathrm{~kg}$ or 10.4 fish per week) than that of small mesh traps $(2.6 \mathrm{~kg}$ or 22.6 fish per week), it was about the same (by weight) as small mesh traps had been in 1990, before the mesh exchange. That increase, coupled with the increased catches by the remaining 1.25 inch traps, ensured that the overall catch per week in 1994, 3 yr after the mesh exchange, exceeded that in 1990. However, fishers still using small mesh traps are benefitting from the recov- 
ery of reef fish populations more than those fishers using large mesh traps. This demonstrates the need for further efforts to eliminate the smaller mesh traps from the fishery, if the full benefits of the mesh exchange are to be realised.

The increased number of fish caught by large mesh traps presumably resulted from an increased abundance of larger fish. This suggests that the reduction in the number of small mesh traps allowed a higher proportion of small fish to avoid capture and to grow large enough to be caught by large mesh traps.

Similarly, the increase in the number of fish caught by small mesh traps suggests an increase in the abundance of small fish. This could be due to a reduction in recruitment overfishing, with at least some species being allowed to grow larger and thus contribute more to the spawning biomass of the population, which could in turn have resulted in increased numbers of juvenile settlers to the reef and subsequently to improved recruitment to the fishery. However, $3 \mathrm{yr}$ is probably too short a time for all this to have occurred in many of the commercially important species (e.g. snappers, groupers and grunts) since several years may elapse between larval settlement and recruitment to the fishery (see Munro 1983, Thresher 1984, Richards \& Lindeman 1987, Roberts 1996, and Sadovy 1996 for reviews of reef fish growth, reproduction and recruitment). An increased number of small fish may also have resulted from greater conspecific attraction of juveniles by an increased number of resident adults. Note however that studies on effects of resident adult fish abundance on the settlement rates of conspecific juveniles have produced contradictory results (see Sale 1976, Williams 1980, Doherty 1983, Shulman 1985, Sweatman 1985, Jones 1987a, b, Stimson 1990, Forrester 1995). Alternatively, given that there were fewer small mesh traps, the increase in the number of fish per haul of the small mesh traps in Discovery Bay could have resulted from a reduction in gear competition.

The increase in mean weight of the catch per haul of both trap types, $3 \mathrm{yr}$ after the implementation of the mesh exchange program, resulted from traps catching more fish and not from either trap type catching larger fish. In fact, the mean size of individual fish in small mesh traps did not change over the period of study, whilst in large mesh traps it actually dropped by $17 \%$. A reduction in the mean size of fish caught may be expected in a growing population, with increased numbers of young fish growing large enough to be caught by the large mesh traps. The fact that mean size of fish in large mesh traps remained considerably larger than in small mesh traps, both immediately after $185 \%$ larger) and $3 \mathrm{yr}$ after the mesh exchange program (67\% larger), is consistent with the findings of previous studies which have addressed mesh selectivity directly and reported that larger mesh traps target larger fish (Bohnsack et al. 1989, Rosario \& Sadovy 1991).

The community structure of fish vulnerable to fish traps in Discovery Bay appeared to undergo few shortterm changes as a result of the implementation of the mesh exchange program, as indicated by the catch composition of small mesh traps in 1990 and 1991. For example, the 2 family groups accounting for the majority of the catch weight of small mesh traps in 1990 (SSC: $27 \%$; ACN: $15 \%$ ), remained similarly important in 1991 (SSC: $39 \%$; ACN: 15\%).

However, the species composition of catches by large mesh traps in 1991, immediately after their introduction, differed slightly from that of small mesh traps in 1991, with 3 groups accounting for the majority of the catch weight (SSC: $23 \%, \mathrm{ACN}: 19 \%$ and LUT: $19 \%)$. This is not surprising given the expected differences in size (and thus species) selectivity of different mesh sizes. It is also consistent with previous comparative fishing experiments which have demonstrated that the species composition of the catch may change substantially with changes in mesh size, primarily due to size selectivity, such that smaller species contribute proportionately less to the catch as mesh size increases (Hunte \& Mahon 1994).

Long-term changes in catch composition at Discovery Bay were more marked than the short-term changes, with the catch composition of both mesh size traps shifting towards larger species groups $3 \mathrm{yr}$ after the implementation of the mesh exchange. For example, in the small mesh traps, LUT replaced $\mathrm{ACN}$ as the second most important group by weight, while the groups SSC, HAM, SSR and MIX also showed significant increases. In the large mesh traps ACN, HAM, and LUT became the 3 most important groups. The long-term shifts in species composition observed since the mesh exchange may therefore indicate an increased availability of larger and deeper-bodied fish to traps, perhaps due to a shift in community structure. Note that the results of earlier studies comparing the species composition of catches of different mesh size traps fished concurrently during relatively short study periods (e.g. Bohnsack et al. 1989, Rosario \& Sadovy 1991) were likely to have been biased by species availability, since sampled populations would not have been in equilibrium with the larger mesh sizes used in these experiments, and therefore it has been suggested that an even higher proportion of large species be expected at equilibrium than was found in these studies (Hunte \& Mahon 1994).

In both trap types, there were long-term increases in CPUE of several groups of carnivorous fish le.g. jacks (CAR), SSR, and HAM]. However the CPUE of herbivorous fish (e.g. SSC, LSC and ACN) did not increase in both trap types. This suggests that all size classes of some carnivorous fish increased in abundance more, 
as a result of the reduction in fishing pressure at Discovery Bay brought about by the mesh exchange program, than did herbivorous fish. Interestingly, decreases in the abundance of piscivorous species have proved to be the most readily detectable effect of increased fishing pressure (e.g. Koslow et al. 1988, Luchavez \& Alcala 1988, Russ \& Alcala 1994, Jennings \& Polunin 1996) whilst large increases in the abundance of carnivorous fish are the first sign of reduced fishing pressure, especially in reserves (e.g. Russ 1985 , Alcala 1988, White 1988, Polunin \& Roberts 1993. Watson \& Ormond 1994, Russ \& Alcala 1996).

The results presented here suggest that the changes observed in catch per haul, catch per week, size of individual fish, and species composition in the Discovery Bay trap fishery $3 \mathrm{yr}$ after the implementation of the mesh exchange program reflect changes in the reef fish populations.

\section{Changes in population size structure}

In order to focus better on the observed changes in fish size, the mean sizes and length-frequency distribution of the 2 most common species in trap catches, the redband parrotfish Sparisoma aurofrenatum and the ocean surgeon Acanthurus bahianus, were examined for changes resulting from the introduction of the larger mesh into the fishery. The 2 species differ in body shape and life history characteristics, and therefore are expected to respond differently to a mesh size change (Munro 1983, Ward 1988, Hunte \& Mahon 1994).

\section{Redband parrotfish}

Redband parrotfish caught in small mesh traps 1 yr and $3 \mathrm{yr}$ after the implementation of the mesh exchange program were significantly larger those caught before and immediately after the implementation of the program. Since the results were obtained from traps of a single mesh size over time, the change in mean size was not due to a change in the size selectivity of the mesh, but appears to represent a shift in the redband parrotfish population toward larger size classes. The pattern of change was similar in the large mesh traps, except that sample sizes were much smaller.

The rapid response of the redband parrotfish population to a change in mesh size is probably a consequence of its narrow, rounded, soft body and ability to squeeze through a mesh (see Ward 1988), resulting in a steeper gear selection curve. This would allow the population to benefit (through a reduction in fishing mortality on small sizes) even from a small increase in the mean mesh size of traps.

\section{Ocean surgeon}

The mean size of ocean surgeon in small mesh traps, on the other hand, was not significantly different in periods before, immediately after and $3 \mathrm{yr}$ after the implementation of the mesh exchange program, and was in fact significantly lower $1 \mathrm{yr}$ after the program was implemented. The pattern was also similar in the large mesh traps. Thus, this deep-bodied species did not appear to benefit, in terms of an increase in mean size, from the increase in mesh size. The decrease in mean size of the ocean surgeon $1 \mathrm{yr}$ after the implementation of the mesh exchange program appears to support the argument that fishing mortality may increase on larger (or deep-bodied) fish after a mesh size increase, if for example fishers alter their fishing behaviour in an attempt to compensate for short-term losses (Hunte \& Mahon 1994). Nevertheless, during the same time period, the weight per haul of all ACN has significantly increased in trap catches, thus the number of $\mathrm{ACN}$ available to the fishery appears to have increased, even if the mean size of individuals has not.

\section{Problems with a single sample}

This study has documented a number of changes in the reef fish populations at Discovery Bay, as reflected in trap catches over the $3 \mathrm{yr}$ following the mesh exchange program. However, one must consider the possibility that factors other than the changes in fishing gear were responsible.

For example, the carrying capacity of the coral reefs for reef fish may have increased significantly during the $4 \mathrm{yr}$ study period. It is true that their carrying capacity declined significantly in the 1980 s due to a loss of 3-dimensional complexity following outbreaks of coral disease and the passing of 2 major hurricanes. Moreover, the structural complexity is not regenerating as a result of a decrease in herbivory due to the mass mortality of Diadema antillarum, and to fishing, which has allowed algae to predominate on the reefs, in what some researchers are calling a new stable state (Liddell \& Ohlhorst 1993, Hughes 1994). We have observed no major change that would have caused an increased carrying capacity between 1990 and 1994 . Furthermore, even if reef carrying capacity had improved, it is unlikely to have resulted in increased abundance of reef fish populations that are severely depressed through overexploitation.

Secondly, the fishing pressure from other gear might have decreased at Discovery Bay since the mesh exchange program was implemented. Casual observation and fisher interviews do not indicate that to be the 
case; indeed, it has more likely increased. It is known, for example, that several spearfishers in Discovery Bay have improved their efficiency over the last $3 \mathrm{yr}$ by employing gill nets to encircle schools of fish to prevent their escape. These efficient, shallow water 'drive-net' operations target the same fish stocks as traps. Therefore, the observed changes in reef fish populations and in the fishtrap catches occurred despite the continually poor state of reefs and the high fishing effort by other gears in Discovery Bay.

Thirdly, there may have been spontaneous increases in fish populations, part of the real but unexplained variability in recruitment and survival due to weather and other variables. In principle, monitoring catch data at a nearby control site with an overexploited trap fishery, with similar additional fishing pressure, and no mesh size change, over the 4 year period may have allowed better interpretation of the observed changes. However, the extra cost and effort that this would have involved was deemed prohibitive, especially given the difficulties of finding a control site to meet the specific criteria. Furthermore, it was felt that entering into the confidence of a second nearby fishing community without encouraging a mesh size increase there would have seriously compromised the trust between the researchers and fishers in the Discovery Bay community.

It is desirable to follow a rigid experimental design in fishery management projects so that the results of monitoring programs can be validated and confident conclusions drawn (McAllister \& Peterman 1992). This is not always possible, yet for reef ecosystems, such as at Discovery Bay, which are believed to be in a critical state near collapse, the urgency of action is so great that local management measures to reduce the degree of overexploitation must be implemented before detailed scientific assessment is performed (Wilkinson 1992). Nonetheless, if existing procedures for the collection of catch and effort data were refined, and observed combinations of gear, effort and catch composition were treated as a series of experimental manipulations, we could begin to elucidate the strategies which have produced desirable yields or shifts (Jennings \& Polunin 1996). The Fisheries Improvement Project's mesh exchange program was one such attempt.

Acknowledgements. This study was supported by grants from the Canadian International Development Agency (CIDA), Hull, Canada; the Coastal Resource Research Network of the International Development Research Centre (IDRC), Ottawa, Canada; the Organization of American States (OAS), Washington, USA; the Canadian University Services Overseas (CUSO), Ottawa; and the Marine Resource and Environmental Management Program (MAREMP) of the University of the West Indies, Cave Hill, Barbados. I. Sandeman of Trent University, Canada, was instrumental in initiating and organizing the Fisheries Improvement Program (FIP) on which this study is based. FIP staff who assisted in data collection were: N. Earle, M. Picou-Gill, M. Miller, W. van Barneveld, S. Vatcher and S. Legate. The trap fishers of Discovery Bay are gratefully acknowledged for their continued support of the mesh exchange program and for participating in the data collection efforts. R. Mahon and 3 anonymous reviewers are thanked for their comments on an earlier draft.

\section{LITERATURE CITED}

Aiken KA (1993) Jamaica. In: FAO (ed) Marine fishery resources of the Antilles: Lesser Antilles, Puerto Rico and Hispaniola, Jamaica, Cuba. FAO Fish Tech Pap 326: $159-180$

Alcala AC (1988) Effects of marine reserves on coral fish abundances and yields of Philippine coral reefs. Ambio 17: $194-199$

Allison WR (1992) The Discovery Bay fisheries improvement project: a status report. Proc Gulf Caribb Fish Instit 42: $331-337$

Berkes F, Shaw AB (1986) Ecologically sustainable development: a Caribbean fisheries case study. Can J Dev Stud 7 : 185-196

Bohnsack JA (1993) The impacts of fishing on coral reefs. In: Global aspects of coral reefs: health, hazards and history. University of Miami, p C8-C12

Bohnsack JA, Sutherland DL, Harper DE, McClellan DB, Hulsbeck MW, Holt CM (1989) The effects of fish trap mesh size on reef fish catch off southeastern Florida. Mar Fish Rev 51:36-46

Burnett-Herkes J, Barnes JA (1991) Banning the use of fish pots and other management methods introduced in Bermuda to protect declining reef fish stocks. Proc Gulf Caribb Fish Inst 44:239-256

Caribbean Fishery Management Council (CFMC) (1985) Fishery management plan, final environmental impact statement, and draft of the regulatory impact review, for the shallow-water reef fish fishery of Puerto Rico and US Virgin Islands. Caribbean Fishery Management Council, Hato Rey

Chakalall B (1992) Fisheries management in the Lesser Antilles. Proc Gulf Caribb Fish Inst 42:294-330

Doherty PJ (1983) Tropical territorial damselfish: is density limited by aggression or recruitment? Ecology 64:175-190

FAO (1993) Marine fishery resources of the Antilles: Lesser Antilles, Puerto Rico and Hispaniola, Jamaica, Cuba. FAO Fish Tech Pap 326, FAO, Rome

Forrester GE (1995) Strong density-dependent survival and recruitment regulate the abundance of a reef fish. Oecologia 103:275-282

Government of Jamaica (1994) Draft principal elements of the Jamaica National Environmental Action Plan. Government of Jamaica, Kingston

Hughes TP (1994) Catastrophes, phase-shifts, and large scale degradation of a Caribbean coral reef. Science 265:1547-1552

Hunte W, Mahon R (1994) Size selection of fish by the mesh of fish traps. Document no. LPRSF SSW/WP/21, CARICOM Fisheries Resource Assessment and Management Project (CFRAMP), Kingstown, St. Vincent

Jennings S, Polunin NVC (1996) Impacts of fishing on tropical reef ecosystems. Ambio 25:44-49

Jones GP (1987a) Competetive interactions among adults and juveniles in a coral reef fish. Ecology 68:1534-1547

Jones GP (1987b) Some interactions between residents and recruits in two coral reef fishes. J Exp Mar Biol Ecol 114: $169-182$ 
Kimmel JJ, Appeldoorn RS (1992) A critical review of fisheries and fishery management policy in Puerto Rico. Proc Gult Carib Fish Inst 41:349-360

Koslow JA, Aiken K, Auil S, Clementson A (1994) Catch and effort analysis of the reef fisheries of Jamaica and Belize. Fish Bull 92:737-747

Koslow JA, Hanley F, Wicklund R (1988) Effects of fishing on reef fish communities at Pedro Bank and Port Royal Cays, Jamaica. Mar Ecol Prog Ser 43:201-212

Liddell WD, Ohlhorst SL (1993) Ten years of disturbance and change on a Jamaican fringing reef. Proc 7 th Int Symp Coral Reefs 1:144-150

Luchavez TF, Alcala AC (1988) Effect of fishing pressure on coral reef fishes in the central Philippines. Proc 6th Int Symp Coral Reefs 2:251-253

Mahon R (1987) Report and proceedings of the Expert Consultation on shared fishery resources of the Lesser Antilles region. Mayaguez, Puerto Rico, 8-12 Sep, 1986. FAO Fish Rep 383

Mahon R (1990) Fishery management options for the Lesser Antilles countries. FAO Fish Tech Pap 313

McAllister MK, Peterman RM (1992) Experimental design in the management of fisheries: a review. $\mathrm{N}$ Am J Fish Manag 12:1-18

Medley PA, Gaudin G, Wells S (1993) Coral reef fisheries stock assessment. Rev Fish Biol Fish 3:242-285

Munro JL (ed) (1983) Caribbean coral reef fishery resources. ICLARM Studies and Reviews 7, Manila

Munro JL (1996) The scope of tropical reef fisheries and their management. In: Polunin NVC, Roberts CM (eds) Reef fisheries. Chapman \& Hall, London, p 1-14

Munro JL, Smith IR (1984) Management strategies for multispecies complexes in artisanal fisheries. Proc Gulf Caribb Fish Inst 36:127-140

Munro JL, Williams DM (1985) Assessment and management of coral reef fisheries: biological, environmental and socioeconomic aspects. Proc 5th Int Coral Reefs Congr 4: $545-581$

National Marine Fisheries Service (NMFS) (1996) Our living oceans. Report on the status of US living marine resources, 1995. US Dep Commer, NOAA Tech Memo NMFS-F/SPO19

Picou-Gill M, Woodley JD, Miller M, Sary Z, van Barneveld W, Vatcher S, Brown D (1991) Catch analysis at Discovery Bay, Jamaica: the status of an artisanal fishery. Proc Gulf Caribb Fish Inst 44:686-693

Polunin NVC, Roberts CM (1993) Greater biomass and value of target coral-reef fishes in two small Caribbean marine reserves. Mar Ecol Prog Ser 100:167-176

Richards WJ, Lindeman KC (1987) Recruitment dymamics of fishes: planktonic processes, settlement and demersal ecologies, and fishery analysis. Bull Mar Sci 41: $392-410$

Roberts CM (1995) Effects of fishing on the ecosystem structure of coral reefs. Conserv Biol 9:988-995

Roberts CM (1996) Settlement and beyond: population regulation and community structure of reef fishes. In: Polunin NVC, Roberts CM (eds) Reef fisheries. Chapman \& Hall, London, p 85-112

Rogers CS (1985) Degradation of Caribbean and Western Atlantic coral reefs and decline of associated fisheries. Proc 5th Int Coral Reefs Congr 6:491-496

Rosario A, Sadovy Y (1991) Trap mesh selectivity off the west coast of Puerto Rico (January 1990-December 1990). Fisheries Research Laboratory, Puerto Rico Department of Natural Resources, Mayaguez

This article was submitted to the editor
Russ GR (1985) Effects of protective management on coral reef fishes in the Central Philippines. Proc 5th Int Coral Reefs Congr 4:219-224

Russ GR (1991) Coral reef fisheries: effects and yields. In: Sale PF (ed) The ecology of fishes on coral reefs. Academia Press, London, p 601-635

Russ GR, Alcala AC (1994) Sumilon Island Reserve: 20 years of hopes and frustration. NAGA, The ICLARM Quarterly, July: $8-12$

Russ GR, Alcala AC (1996) Marine reserves: rates and patterns of recovery and decline in abundance of large predatory fish. Ecol Appl 6:947-961

Sadovy YJ (1996) Reproduction of reef fishery species. In: Polunin NVC, Roberts CM (eds) Reef fisheries. Chapman \& Hall, London, p 15-59

Sale PF (1976) The effects of territorial adult pomacentrid fishes on the recruitment and survival of juveniles on patches of coral rubble. J Exp Mar Biol Ecol 24: 297-306

Sale PF, Forrester GE, Levin PS (1994) Reef fish management. Res Explor 10:224-235

Sandeman IM, Woodley JD (1994) Jamaica North Coast Fisheries Improvement Project - final report to the Canadian International Development Agency. CIDA Report No. 504/13778. CIDA, Ottawa

Sary Z (1995) Responses of an over-exploited Caribbean trap fishery to the introduction of a larger mesh size, in Discovery Bay, Jamaica. MSc thesis, University of the West Indies, Cave Hill, Barbados

Sary Z, Miller M, van Barneveld W, Picou-Gill M, Woodley JD (1991) Facilitating change in artisanal fishery practice: the two-for-one trap exchange program at Discovery Bay, Jamaica. Proc Gulf Caribb Fish Inst 44:283-296

Shulman MJ (1985) Variability in recruitment of coral reef fishes. J Exp Mar Biol Ecol 89:205-219

Stimson JS (1990) Density dependent recruitment in the reef fish Chaetodon milaris. Environ Biol Fish 29:1-13

Sweatman HPA (1985) The influence of adults of some coral reef fishes on larval recruitment. Ecol Monogr 55:469-485

Thresher RE (1984) Reproduction in reef fishes. TFH Press, Neptune City, NJ

Ward J (1988) Mesh size selection in Antillean arrowhead fish traps. In: Venema S, Moller-Christensen J, Pauly D (eds) Contributions to tropical fisheries biology. FAO Fish Rep 389:455-467

Watson M, Ormond RFG (1994) Effect of an artisanal fishery on the fish and urchin populations of a Kenyan coral reef. Mar Ecol Prog Ser 109:115-129

White AT (1988) The effect of community-managed marine reserves in the Philippines on their associated coral reef fish populations. Asian Fish Sci 2:27-41

Wilkinson CM (1992) Coral reefs of the world are facing widespread devastation: can we prevent this through sustainable management practices? Proc 7 th Int Symp Coral Reefs 1:11-21

Williams DM (1980) Dynamics of the pomacentrid community on small patch reefs in One Tree Lagoon. Bull Mar Sci 30: $159-170$

Woodley JD (1994) Facilitating changes in artisanal fishery practice at Discovery Bay, Jamaica. In: Munro JL, Munro PE (eds) The management of coral reef resource systems. ICLARM Conference Proceedings XX, ICLARM, Manila, p 75-78

Woodley JD, Robinson E (1977) Field guide book to the modern and ancient reefs of Jamaica. 3rd Internation Symposium on Coral Reefs, Atlantic Reef Committee, Fisher Island, Miami Beach, FL

Manuscript received: September 26, 1996

Revised version accepted: April 30, 1997 